\title{
Arm Randomization Weight
}

National Cancer Institute

\section{Source}

National Cancer Institute. Arm Randomization Weight. NCI Thesaurus. Code C93730.

The relative proportion of subjects to be randomized to the arm. 